D.O.I: $10.3895 / \mathrm{S} 1808-04482012000300008$

\title{
ANÁLISE COMPARATIVA DE APLICAÇÃO DE METODOLOGIA DE GERENCIAMENTO DE PROJETOS EM UMA GRANDE EMPRESA MINERADORA
}

\author{
COMPARATIVE ANALYSIS OF APPLICATION OF PROJECT \\ MANAGEMENT METHODOLOGY IN A LARGE MINING COMPANY
}

\author{
Mariana Moura Abreu ${ }^{1}$; Teresa Cristina Janes Carneiro ${ }^{2}$ \\ ${ }^{1}$ Universidade Federal do Espírito Santo - UFES - Vitória - Brasil \\ mariana.m.abreu@hotmail.com \\ ${ }^{2}$ Universidade Federal do Espírito Santo - UFES - Vitória - Brasil \\ carneiro.teresa@gmail.com
}

\begin{abstract}
Resumo
A utilização de metodologias de gerenciamento de projetos pode possibilitar aos profissionais envolvidos com projetos a execução de suas atividades com maior eficiência e eficácia. $O$ estudo buscou identificar as ações utilizadas no planejamento, monitoramento e controle de projetos, o nível de envolvimento dos gestores com as ferramentas de gerenciamento de projetos e o resultado de utilização desta forma de gestão em prol do sucesso dos projetos. O método de pesquisa utilizado foi o estudo de caso em três gerências de uma grande empresa mineradora: Gerência de Serviços de Infra-Estrutura, Gerência de Implantação de Projetos Ligados à Produção e a Gerência de Desenvolvimento de Tecnologia de Informação. As gerências foram escolhidas por serem prestadoras de serviços internos à empresa e responsáveis por vários projetos. Foram entrevistados três gestores de projetos, nas três gerências analisadas. Os resultados mostraram a importância da aplicação de metodologia de gerenciamento de projetos, independente da dimensão do projeto para cumprimento de prazos, orçamento e obtenção da qualidade desejada. Uma caracterísitca observada nos projetos analisados foi a autonomia dos clientes para reestruturação do planejamento. Porém o excessivo atendimento às solicitações do cliente pode causar constantes revisões e acarretar ciclos de vida aparentemente distorcidos. Contudo, o que torna uma área de gerenciamento de projetos eficaz é saber realizar a gestão de seu planejamento em conjunto com a necessidade e expectativa do cliente para que seus produtos sejam entregues com a qualidade solicitada e esperada pelo cliente.
\end{abstract}

Palavras-chave: Projetos; Gestão de Projetos; Metodologia; Planejamento; PMI.

\section{Introdução}

O ambiente organizacional sofre mudanças diárias tanto na criação de novos produtos e serviços, quanto na busca constante pela eficácia de resultados obtidos. Essas mudanças aumentam a exigência das organizações diante do acompanhamento do mercado para garantia da 
sobrevivência e manutenção da competitividade. Para tanto, é fundamental a adoção de uma forma de organização clara, objetiva e com qualidade das atividades executadas. O Gerenciamento de Projetos intensifica o controle da entrega de novos produtos ou serviços. Adotar uma metodologia específica de gerenciamento de projetos facilita a execução de resultados com sucesso nas organizações.

Com crescimento de complexos industriais no decorrer dos últimos anos, houve um aumento da relevância da adoção de metodologias de Gestão de Projetos em todas as organizações, equalizando a criticidade da área de produção e operação com as demais áreas internas. A conscientização organizacional de que projetos de engenharia e de tecnologia de informação geram custos e impactam o produto final com a mesma intensidade que a área de produção, alertou as organizações para a importância de implantar e centralizar o gerenciamento de projetos para fins de controle econômico e da qualidade.

Verificando a crescente necessidade de implantação bem-sucedida de projetos, o objetivo deste trabalho foi identificar a aplicação de metodologias de gerenciamento de projetos em áreas prestadoras de serviços internos em uma grande empresa mineradora, apontando as deficiências e boas práticas dos projetos analisados, por meio de análises de risco, custo, tempo e qualidade desses projetos sugerindo, assim, oportunidades de melhorias.

\section{Projetos}

O Guia PMBOK do PMI (2004) define projeto como "um esforço temporário empreendido para criar um produto, serviço ou resultado exclusivo." Para Valeriano (2003), projeto é “um conjunto singular de atividades coordenadas, com início e término definidos, empreendido por um indivíduo ou uma organização, para atingir objetivos específicos, com cronograma, custo e desempenho determinados". Segundo Valeriano (2005), os projetos e as operações se diferem em diversas características, principalmente no fato de que as operações são contínuas e repetitivas, enquanto os projetos são temporários e exclusivos.

A relação entre projeto e operação também pode ser assumida como uma relação complementar. A finalidade do projeto é atingir seu objetivo e entregar seu produto, serviço ou resultado. Por outro lado, o objetivo de uma operação é de continuidade, manter o negócio, o produto, serviço ou o resultado.

\section{Fatores críticos de sucesso de projetos}

Tem havido muitas tentativas nos últimos anos de identificar os fatores críticos que indiquem o sucesso ou fracasso de projetos. Diferentes pesquisadores tentaram determinar esses fatores em várias áreas (COOKE-DAVIES, 2002; CHAN; SCOTT; CHAN, 2004; JUGDEV; 
MÜLLER, 2005; RODRIGUEZ-REPISOA; SETCHIB; SALMERONC, 2007; PINTO; SLEVIN, 2008; DENNI-FIBERESIMA; RANI, 2011; LAVAGNON; DIALLO; THUILLIER, 2012), no entanto, mesmo com uma abordagem conservadora, a lista é muito longa. Os fatores de sucesso não são universais para todos os projetos. Em diferentes contextos, o significado de fatores semelhantes pode variar (BALACHANDRA; FRIAR, 1997). Projetos diferentes apresentam diferentes conjuntos de fatores de sucesso (DVIR; LIPOVETSKY; SHENHAR; TISHLER, 1998). Há muitas técnicas para gerenciar e ajudar a garantir o sucesso do projeto. Algumas dessas técnicas, no entanto, podem não ser adequadas para tipos específicos de projetos e, assim, contribuir para o insucesso desses projetos (ATTARZADEH; OW, 2008).

Entre os critérios mais comumente citados estão o grau de atendimento dos objetivos do projeto, o esforço de gestão e o cumprimento de prazo, custo e qualidade. Wit (1988) defende que é essencial fazer uma distinção entre o sucesso do projeto e o sucesso do esforço de gerenciamento de projetos, levando em conta que uma boa gestão de projetos pode contribuir para o sucesso do projeto, mas nem sempre é capaz de prevenir falhas. Para Munns e Bjeirmi (1996), no gerenciamento de projetos, devem-se considerar os diferentes sujeitos envolvidos, juntamente com os seus objetivos, expectativas e influências.

Fatores como estilo de liderança (TURNER, MÜLLER, 2005), envolvimento (JONAS, 2010), conscientização e abertura do gerente de projeto (BEDINGFIELD; THAL Jr., 2008), competência em comunicação (HENDERSON, 2004), gestão da informação e de riscos lançam uma luz sobre os comportamentos dos gerentes de projeto e de como esses comportamentos podem auxiliar a prever o sucesso ou fracasso de um empreendimento. Há ainda características particulares dos gestores tais como competências e habilidades que também são citados (KUEN; ZAILANI; YUDI, 2009; MÜLLER; TURNER, 2010; SUHONEN; PAASIVAARA, 2011), assim como o ajuste entre o projeto, a personalidades dos gestores e as "personalidades" dos projetos (MALACHPINES; DVIR; SADEH, 2009).

Chua, Kog e Loh (1999) agrupam os fatores-chave para o sucesso do projeto sob quatro aspectos principais, nomeadamente, as características do projeto, os arranjos contratuais, os participantes do projeto e os processos interativos na hierarquia. Fatores críticos de sucesso abordando a simplificação, a padronização, a alocação de talentos na equipe e a qualificação dos membros da equipe (TISHLER; DVIR; SHENHAR; LIPOVETSKY, 1996) também são citados para grandes projetos (PATÉ-CORNELL; DILLON, 2001). A compreensão das necessidades dos clientes (LIM; ZAIN, 1999), o envolvimento do fornecedor no processo de desenvolvimento, participação do usuário no processo de design (HOPE; AMDAHL, 2011), o gerenciamento de aquisições (NELLORE; BALACHANDRA, 2001), os benefícios de curto e longo prazos para o negócio (SAVOLAINEN; AHONEN; RICHARDSON, 2012), estabelecimento de confiança para o 
cliente, custo de execução realista, bem como um resultado inovador sustentável (LOVE; MISTRY; DAVIS, 2010) e o uso de uma metodologia internacionalmente reconhecida (MCHUGH; HOGAN, 2011) também são citados.

Wateridge (1995) defende que os gerentes de projeto geralmente se concentram em atingir prazos e orçamentos. Os projetos para serem bem sucedidos precisam de critérios de sucesso definidos de forma clara e acordados por todas as partes no início e revistos no decorrer do projeto. Defende ainda que os gerentes de projeto devem se concentrar mais em critérios de sucesso relacionados aos usuários e patrocinadores.

\section{Gerenciamento de projetos}

De acordo com PMBOK (PMI, 2004), Gerenciamento de Projeto consiste em aplicar conhecimento, habilidades, ferramentas e técnicas às atividades pertencentes ao projeto para alcançar os seus requisitos. Este gerenciamento se dá segundo um ciclo de vida que inclui iniciação, planejamento, execução, monitoramento e controle e encerramento. Para Vieira (2003), não é possível atender os requisitos do gerenciamento de projetos se não houver o controle, que pode ser considerado o principal ponto do conceito. O objetivo deste gerenciamento é garantir o cumprimento do escopo, dos prazos, dos custos e da entrega dos produtos com a qualidade estipulada pelo cliente.

Um termo mencionado com freqüência pelos gerentes de projetos é "Restrição tripla" escopo, tempo e custo do projeto - que consiste em balancear essas partes conflitantes que tendem a integrarem-se a todo o tempo, durante as etapas do projeto. A qualidade também é afetada no entrelaçamento desses fatores. Tal envolvimento é tão direto que qualquer mudança ocorrida em um dos fatores, conseqüentemente, afetará um dos outros fatores envolvidos. Uma habilidade esperada de um gerente de projeto, portanto, é o gerenciamento de respostas às incertezas, o chamado risco do projeto. Este pode ser definido como um evento ou condição incerta que, em caso de ocorrência, terá um efeito positivo ou negativo em pelo menos um objetivo do projeto.

Em quase sua totalidade, os projetos possuem um desvio, mesmo que mínimo, em seu planejamento de custo, tempo, escopo e qualidade. É preciso entender e conhecer os projetos individualmente a fundo para que se possa conceituar um fracasso ou sucesso de um projeto. Kelling (2002) afirma que os projetos fracassam ou são abjurados por diversas razões e grande maioria resulta apenas em um sucesso parcial, quando os objetivos não são alcançados no prazo, os custos aumentam além dos limites aceitáveis, ou os níveis estabelecidos de qualidade ou realização ficam comprometidos.

É inviável identificar todas as áreas que podem contribuir para o insucesso de um projeto devido às incertezas que surgem diariamente no cenário organizacional. Um rastreamento profundo 
realizado em um estudo de um projeto específico resulta uma menor dificuldade em detectar os pontos que decorrem o fracasso no projeto, entretanto não é possível relacionar todos os pontos possíveis e existentes que comprometem o resultado do projeto, pois não se podem tratar todos os projetos como similares. Cada um possui sua particularidade, tanto no produto ou serviço quanto nas áreas de conhecimentos existentes e no ambiente na qual se encontram inseridos.

De acordo com o PMBOK (PMI, 2004), o gerenciamento de projetos envolve nove áreas de conhecimento: integração, escopo, tempo, custo, qualidade, recursos humanos, comunicações, riscos e aquisições do projeto. Destacam-se quatro áreas centrais que são assim consideradas por terem ligação direta com os objetivos do projeto: escopo, tempo, custo e qualidade. Destacam-se também quatro áreas facilitadoras, por serem os meios de se alcançar os objetivos do projeto: recursos humanos, comunicação, riscos e aquisições do projeto, e uma área integradora que possui o encargo de garantir que todas as outras áreas sejam integradas como um todo, e permite que o projeto seja estruturado com a garantia de que as necessidades dos envolvidos sejam acatadas (Figura 1).

Figura 1 - Relação das Áreas de Conhecimento.

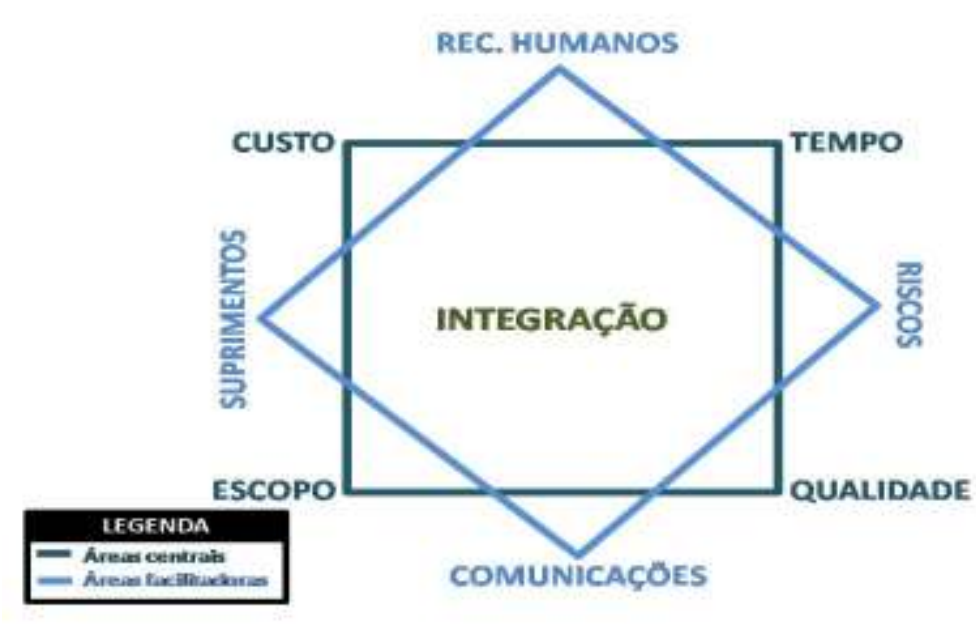

Fonte: PMBOK (PMI, 2004),

De acordo com Metodologia de PMI, as nove áreas de gerenciamento de projetos são:

- Gerenciamento de integração do projeto: Inclui processos e atividades necessárias para identificar, definir, combinar, unificar e coordenar os diversos processos e atividades do gerenciamento de projetos. Caracterizada pela existência de ações integradoras que se tornam essenciais para o término do projeto, atendendo a necessidade do cliente e das demais partes interessadas;

- Gerenciamento do escopo: Trata-se de um processo que garanta que o projeto inclua todo o trabalho necessário, e somente ele, para terminar o projeto com sucesso. Abrange principalmente a definição e controle do que está e do que não está incluído no projeto; 
- Gerenciamento do tempo: Inclui os processos necessários para realizar o término do projeto dentro do prazo;

- Gerenciamento do custo: Abrange o planejamento, estimativa, ornamentação e controle dos custos, para que seja possível o termino do projeto dentro do prazo aprovado;

- Gerenciamento da qualidade: Seus processos incluem todas as atividades da organização executora que determinam as responsabilidades, os objetivos e as políticas de qualidade, para que o projeto garanta às necessidades que motivaram sua realização;

- Gerenciamento de recursos humanos: Seu processo inclui o gerenciamento da equipe do projeto. A equipe de projeto é composta de pessoas com funções e responsabilidades atribuídas para o término do projeto;

- Gerenciamento das comunicações: Área de conhecimento que emprega os processos necessários para garantir a geração, coleta, distribuição, armazenamento, recuperação e destinação final das informações sobre o projeto de forma oportuna e adequada. Seus processos fornecem as ligações críticas entre pessoas e informações que são necessárias para comunicações bemsucedidas;

- Gerenciamento dos riscos: Incluem os processos que tratam da identificação, análise, respostas, monitoramento e controle e planejamento do gerenciamento de riscos em um projeto. Essa área de conhecimento tem o objetivo de aumentar a probabilidade e o impacto dos eventos positivos e diminuir a probabilidade e o impacto dos eventos adversos ao projeto;

- Gerenciamento de aquisições: Inclui os processos de comprar e adquirir produtos, serviços, processos de gerenciamento de contratos e do controle de mudanças nos contratos.

\section{Metodologia}

O estudo buscou identificar as formas utilizadas para o planejamento, monitoramento e controle dos projetos analisados, o nível de envolvimento dos gestores com as ferramentas de gerenciamento de projetos e o resultado de utilização desta forma de gestão em prol do sucesso dos projetos. Como o tema abordado tem uma evolução de conhecimento e descobertas constantes devido a sua inovação, a pesquisa assumiu um caráter exploratório. Foi realizada com três gestores de projetos de três gerências de área de uma grande empresa mineradora. As três áreas estudadas, Gerência de Serviços de Infra-Estrutura (GSIE), Gerência de Implantação de Projetos ligados à Produção (GIPP) e a Gerência de Desenvolvimento de Tecnologia de Informação (GDTI) atuam na prestação de serviços internos à empresa. A Quadro 1 a seguir resume as informações sobre áreas e projetos selecionados para análise. 
Quadro 1 - Gerências e Projetos escolhidos para análise

\begin{tabular}{|c|c|c|c|}
\hline Áreas & Sigla & Escopo & Projeto Analisado \\
\hline $\begin{array}{l}\text { Gerência de } \\
\text { Serviços de Infra- } \\
\text { Estrutura }\end{array}$ & GSIE & $\begin{array}{l}\text { Projetos estruturais (obras) de pequeno porte e } \\
\text { serviços rotineiros de manutenção básicos, } \\
\text { como saneamento, condomínio, alimentação e } \\
\text { transporte (serviços de apoio aos profissionais } \\
\text { internos). }\end{array}$ & $\begin{array}{l}\text { Reforma do Edifício da Cúpula } \\
\text { Executiva da Empresa, onde } \\
\text { funcionam os escritórios da } \\
\text { presidência e diretoria da empresa }\end{array}$ \\
\hline $\begin{array}{c}\text { Gerência de } \\
\text { Implantação de } \\
\text { Projetos ligados à } \\
\text { Produção }\end{array}$ & GIPP & $\begin{array}{l}\text { Projetos estruturais (obras) ligados à produção } \\
\text { e para atendimento a condicionantes } \\
\text { ambientais. Foi constituída exclusivamente } \\
\text { para gerenciar projetos que surgem pela } \\
\text { necessidade de crescimento e modernização } \\
\text { do complexo industrial. }\end{array}$ & $\begin{array}{c}\text { Reforma do Restaurante Central do } \\
\text { Complexo Industrial }\end{array}$ \\
\hline $\begin{array}{l}\text { Gerência de } \\
\text { Desenvolvimento } \\
\text { de Tecnologia de } \\
\text { Informação }\end{array}$ & GDTI & $\begin{array}{l}\text { Projetos ligados a tecnologia de informação } \\
\text { (TI) para atender clientes internos, diante da } \\
\text { necessidade de crescimento e garantia de } \\
\text { competitividade da empresa no cenário atual. }\end{array}$ & $\begin{array}{l}\text { Novo Sistema de Informação: } \\
\text { aquisição de hardware, licenças de } \\
\text { software básico, desenvolvimento } \\
\text { de software sob medida e } \\
\text { treinamento de usuários }\end{array}$ \\
\hline
\end{tabular}

Fonte: Autoria própria (2011)

Embora a empresa possua diversas gerências executoras de projetos, o estudo selecionou as três áreas conhecedoras e aplicadoras da metodologia de Gerenciamento de Projetos do PMI, uma evoluindo na implantação de escritório de projetos e as demais com aplicação da metodologia individualmente pelos gestores de projeto existentes nas áreas. Os três projetos escolhidos, um de cada gerência, estavam concluídos na data da pesquisa, permitindo uma comparação de todas as etapas do gerenciamento de projetos entre as três gerências estudadas.

As entrevistas semi-estruturadas realizadas com os gestores de projetos das três gerências ocorreram no período de setembro e outubro de 2008 com duração média entre 40 minutos e uma hora e 30 minutos.

\section{Contextualização das áreas estudadas}

Com o intuito de dimensionar as três áreas estudadas, bem como identificar a dimensão de custos, tempo e recursos envolvidos nas atividades dessas gerências, elaborou-se a Quadro 2 a seguir que traça um perfil de cada gerência e as compara entre si.

Quadro 2 - Perfil das Gerências estudadas

\begin{tabular}{|c|c|c|c|}
\hline \multirow{2}{*}{ Características Analisadas } & \multicolumn{3}{|c|}{ Gerências estudadas } \\
\cline { 2 - 4 } & GSIE & GIPP & GDTI \\
\hline Custo médio dos projetos da gerência & Menor & Maior & Maior \\
\hline Fornecedores - Quantidade/ projeto & Menor & $\begin{array}{c}\text { Quase total } \\
\text { exclusividade }\end{array}$ \\
\hline $\begin{array}{c}\text { Fornecedores - Exclusividade de } \\
\text { atendimento à gerência }\end{array}$ & Sem exclusividade & Sem exclusividade & Moderado \\
\hline Ciclo de vida médio dos projetos & Menor & $\begin{array}{c}\text { Maior } \\
\text { planta industrial }\end{array}$ & $\begin{array}{c}\text { Obras na planta } \\
\text { industrial }\end{array}$ \\
\hline $\begin{array}{c}\text { Tipo de produto fornecido pelos } \\
\text { projetos }\end{array}$ & Moderado & Maior & Menor \\
\hline Quantidade de projetos demandados & & & \\
\hline
\end{tabular}




\begin{tabular}{|c|c|c|c|}
\hline \multirow{2}{*}{ Características Analisadas } & \multicolumn{3}{|c|}{ Gerências estudadas } \\
\cline { 2 - 4 } & GSIE & GIPP & Sim \\
\hline $\begin{array}{c}\text { Participação de outras gerências nos } \\
\text { projetos da gerência }\end{array}$ & Sim & $20 \%-80 \%$ & $20 \%-80 \%$ \\
\hline $\begin{array}{c}\text { Recursos Humanos próprios e } \\
\text { terceirizados }\end{array}$ & $15 \%-85 \%$ & SPE, IPA, PMI & PMI adaptado \\
\hline $\begin{array}{c}\text { Metodologias de gerenciamento de } \\
\text { projetos utlizadas }\end{array}$ & PMI adaptado & $100 \%$ \\
\hline $\begin{array}{c}\text { Percentual de projetos em relação as } \\
\text { atividades da gerência }\end{array}$ & $\begin{array}{c}\text { Necessidade de } \\
\text { cresci-mento da } \\
\text { empresa }\end{array}$ & $\begin{array}{c}\text { Necessidade de } \\
\text { crecimento e } \\
\text { modernização da planta } \\
\text { industrial }\end{array}$ & $\begin{array}{c}\text { Necessidade de } \\
\text { crescimento da } \\
\text { empresa e moder- } \\
\text { nização da gestão }\end{array}$ \\
\hline
\end{tabular}

Fonte: Autoria própria (2011)

As três gerências possuem portes financeiros distintos na execução de projetos. A GIPP tem o maior envolvimento de custos, acompanhada pela GDTI e em seguida pela GSIE, com uma proporção de 100:10:1. Essa diferença de custos está relacionada ao porte dos projetos de cada gerência. A GIPP é responsável por projetos estruturais de grande porte e a GSIE, projetos estruturais de menor porte. A GDTI é responsável por serviços de TI.

\subsection{Fornecedores envolvidos e etapas de participação}

As gerências de grande e médio porte financeiro, GIPP e GDTI respectivamente, possuem aproximadamente a mesma quantidade de fornecedores envolvidos e em etapas semelhantes do gerenciamento de projetos. O fornecedor principal auxilia no gerenciamento: há sempre um gerente de projeto na contratante e um gerente de projeto na contratada. Ambos estão focados no cumprimento de todas as obrigações contratuais do projeto. Possuem seus fornecedores presentes nas etapas ligadas à execução dos projetos, desde a própria gestão até a parte operacional do projeto, contribuindo com o planejamento, monitoramento e controle das etapas. A GSIE, de pequeno porte, possui uma quantidade de fornecedores envolvidos menor. Quanto maior o envolvimento financeiro, maior o porte dos projetos executados e maior a quantidade de recursos humanos envolvidos nos projetos, direta ou indiretamente. Contudo, houve uma semelhança nas três gerências estudadas quanto à participação dos fornecedores. Em todas as gerências, existia a atuação de uma empresa contratada como gerenciadora, que tinha o papel de realizar o gerenciamento de projetos junto às gerências. Porém, isso não elimina a responsabilidade dos gestores de projetos.

As gerenciadoras (empresas contratadas) das três áreas estudadas possuíam suas atividades voltadas para a execução das etapas dos projetos, acompanhamento dessas atividades e fornecimento de informações para os gestores da empresa estudada. O gerenciamento de projetos não é um papel designado exclusivamente aos gestores da empresa estudada. Existe uma relação 
horizontal destes com os gestores das contratadas, entretanto, a autonomia para a tomada de decisões finais ainda permanece na organização principal, como forma de não perder o controle do andamento das etapas. As responsabilidades por qualquer decisão tomada será sempre da empresa contratante. É ela quem assumirá qualquer responsabilidade diante de conseqüências positivas ou negativas que o projeto venha a gerar. A maior parte dos fornecedores lida com a parte operacional do projeto, em colocar em prática o que foi estabelecido, de acordo com orientações e aval do gestor da empresa contratante.

\subsection{Fornecedores como prestadores de serviços exclusivos}

A GDTI se destacou no quesito de prestação de serviços exclusivos dos fornecedores para sua gerência. Essa exclusividade não é imposição da gerência, mas sim pelo fato de existir uma centralização dos serviços de TI dentro da organização. A não existência dessa exclusividade nas demais gerências estudadas mostra que, apesar de possuírem focos distintos, seus produtos são, em sua maioria, similares. Ambas possuem obras como produto dos projetos, porém a GSIE possui foco em serviços às áreas comuns e compartilhadas, enquanto a GIPP possui foco em obras ligadas à produção (usinas). Essa exclusividade encontrada na GDTI pode ser um fator positivo, visto que não possui risco dos fornecedores dividirem ou remanejarem seus profissionais para execução de atividades em outras gerências. O que se vê na empresa são fornecedores com contratos simultâneos com áreas diferentes da empresa, impedindo assim a questão de exclusividade na prestação de serviços para uma área.

\subsection{Ciclo de vida dos projetos e suas relações}

A GSIE lida com projetos mais rápidos e curtos, com duração média de 3 a 6 meses. A GDTI possui seu ciclo de vida em torno de 14 meses e a GIPP, de maior porte financeiro, se enquadra na de maior ciclo de vida, em média. [...] A GIPP, por ser uma gerência de atuação exclusiva em projetos, elabora seu planejamento e ciclo de vida de cada projeto de acordo a solicitação do serviço pelo cliente. Nos projetos executados por essa gerência, pode-se ter ciclos de vida reajustados, mas quando isso é solicitado informa-se ao cliente que o reajuste no tempo acarretará um envolvimento financeiro maior. A escolha passa a ser do cliente. O mesmo não acontece com a GSIE. Muitas vezes os projetos têm seu tempo reajustado por solicitação do cliente e seus custos não podem ser reajustados. Com isso, a gerência não possui recursos financeiros para mais alocação de mão-de-obra que acompanhe o reajuste do ciclo de vida. Esses projetos passam a ser prioritários quanto a sua execução, fazendo com que o planejamento dos demais projetos seja refeitos, postergando o início de execução dos demais ou paralisando os já iniciados. Assim, inicia- 
se uma série de conflitos, porque todos os clientes vêem seus projetos como prioritários, acarretando insatisfação de uma maioria para a satisfação de uma minoria.

\subsection{Demanda de projetos e suas relações}

Apesar do envolvimento financeiro da GIPP ser maior, a média de projetos realizados por ano é a menor dentre as três gerências estudadas, em uma proporção de 25:16:5 (GDTI:GSIE:GIPP). A alta quantidade de projetos executados anualmente na GDTI se dá pela centralização nessa gerência de todos os serviços de tecnologia de informação na organização. Porém a relação de demanda de projetos não está diretamente relacionada à centralização do serviço. Se a área de TI fosse descentralizada, talvez a quantidade total de projetos fosse ainda maior, porque não haveria reaproveitamento, nem padronização, podendo haver redundâncias de esforços. Já as demais gerências em estudo, devido ao tipo de produto gerado nos projetos, a organização não teria uma vantagem aparentemente considerável se ocorresse uma centralização. Não seria evitado um retrabalho, por exemplo, se duas obras distintas fossem gerenciadas pela mesma gerência. De qualquer forma, as duas obras teriam que ser executadas. Talvez o que poderia ser reduzido seria o custo financeiro na contratação do serviço de mão-de-obra para execução operacional. Pois quanto maior for o quantitativo para contratação, maior seria a possibilidade da equipe responsável pela contratação negociar os preços dos serviços.

A baixa demanda da GSIE está diretamente relacionada ao escopo central da gerência. A gerência não executa apenas projetos, mas também manutenções consideradas rotineiras (70\% de suas atividades). A existência da necessidade que a GSIE tem de se ajustar a imposições de prazos dos clientes, deve-se ao fato de ser uma área prestadora de serviços. Os clientes vêem a gerência, acima de tudo, como prestadora de serviços de manutenção e obras e, talvez por isso, se permitam fazer imposições quanto ao tempo de execução dos projetos.

\subsection{Risco em projetos}

A GSIE focaliza seu gerenciamento, principalmente, nos riscos. Não somente seus projetos, mas outras atividades rotineiras são oriundas das necessidades e solicitações de seus clientes. Portanto, o atendimento a todos os pontos pré-estabelecidos durante o planejamento do projeto é cobrado freqüentemente pelos clientes. Um detalhado e criterioso gerenciamento de riscos previnem o gestor de surpresas desagradáveis que não satisfaçam as necessidades dos clientes, desestabilizando todo o planejamento das demais áreas de conhecimento como o custo, tempo e qualidade. Contudo, apesar dessa imensa preocupação com o gerenciamento dos riscos dos projetos, a GSIE não atribui as demais áreas de conhecimento como irrelevantes. O que se acredita é a importância que vêem na satisfação do cliente quanto ao cumprimento do planejamento, e para isso 
é indispensável um bom gerenciamento dos riscos passíveis de ocorrência durante a execução do projeto. O principal, e comum a todas as gerências, é a satisfação do cliente. É isso que determina para eles o sucesso ou o fracasso do projeto, visto que são gerências prestadoras de serviços.

\section{Comparação entre os projetos das três gerências}

Com o intuito de identificar e comparar os três projetos analisados, um de cada área, elaborou-se a Quadro 3 a seguir:

Quadro 3 - Comparação entre Projetos

\begin{tabular}{|c|c|c|c|}
\hline Item & Projeto GSIE & Projeto GIPP & \begin{tabular}{|l} 
Projeto GDTI \\
\end{tabular} \\
\hline Nome & $\begin{array}{l}\text { Reforma do Edifício da Cúpula } \\
\text { Executiva da Empresa }\end{array}$ & $\begin{array}{l}\text { Ampliação da Cozinha do } \\
\text { Restaurante Central }\end{array}$ & $\begin{array}{l}\text { Novo Sistema de Informação: } \\
\text { aquisição de hardware, soft-ware } \\
\text { e treinamento }\end{array}$ \\
\hline Escopo & $\begin{array}{l}\text { Houve várias alterações durante } \\
\text { execução }\end{array}$ & $\begin{array}{c}\text { Premissas mal definidas. } \\
\text { Houve três alterações } \\
\text { durante a execução }\end{array}$ & Não houve alteração \\
\hline Custo & $\begin{array}{c}\text { Reserva financeira para } \\
\text { emergências / imprevistos em } \\
\text { função do prazo. Objetivo } \\
\text { menor custo possível }\end{array}$ & $\begin{array}{l}\text { Aumento de } 3 \% \text { em relação } \\
\text { ao previsto devido a } \\
\text { alteração do escopo na } \\
\text { execução do projeto }\end{array}$ & $\begin{array}{c}\text { Rredução de } 5,2 \% \text { em relação ao } \\
\text { previsto devido a queda nos } \\
\text { preços de bens e servi-ços e } \\
\text { variação cambial }\end{array}$ \\
\hline Prazo & $\begin{array}{c}\text { Apertado. Estabelecido pelo } \\
\text { cliente e ajustado pela gerência } \\
\text { executora }\end{array}$ & $\begin{array}{l}\text { Apertado. Estabelecido pelo } \\
\text { cliente e ajustado pela } \\
\text { gerência executora }\end{array}$ & $\begin{array}{c}\text { Estabelecido pela gerência } \\
\text { executora. Sofreu acrés-cimo de } \\
1 \% \text { na execução devido a demora } \\
\text { na entre-ga de bens e serviços de } \\
\text { terceiros }\end{array}$ \\
\hline Qualidade & $\begin{array}{l}\text { Importante devido a } \\
\text { proximidade da } \\
\text { presidência/diretoria }\end{array}$ & $\begin{array}{l}\text { Não havia equipe } \\
\text { responsável pelo controle de } \\
\text { quali-dade. Não foi con- } \\
\text { siderado fator crítico }\end{array}$ & $\begin{array}{l}\text { Preocupação com a qualidade dos } \\
\text { equipamentos e com atendimento } \\
\text { da expectativa do cliente em } \\
\text { relação a funcionalidade do } \\
\text { sistema }\end{array}$ \\
\hline Contratação & $\begin{array}{c}\text { Apenas contratação da em-presa } \\
\text { terceirizada, res-ponsável por } \\
\text { todas as outras contatações }\end{array}$ & $\begin{array}{l}\text { Diretamente pela empresa. } \\
\text { Demanda-da pelo gestor do } \\
\text { projeto }\end{array}$ & $\begin{array}{c}\text { Pela gerência de TI e fornece- } \\
\text { dores de bens e serviços } \\
\text { (exclusivos da área) }\end{array}$ \\
\hline Comunicação & $\begin{array}{c}\text { Gestor do projeto comunicava- } \\
\text { se com responsável da } \\
\text { contratada } \\
\end{array}$ & $\begin{array}{c}\text { Por meio de reuniões } \\
\text { semanais, registradas em ata } \\
\text { com toda a equipe } \\
\end{array}$ & $\begin{array}{c}\text { Por meio de reuniões quinzenais, } \\
\text { registradas em ata com toda a } \\
\text { equipe }\end{array}$ \\
\hline Estrutura & $\begin{array}{l}\text { Centralização do controle do } \\
\text { andamento. Em caso de } \\
\text { mudanças, caminho para } \\
\text { solução era longo. }\end{array}$ & $\begin{array}{l}\text { Alterações executadas se } \\
\text { autorizadas pelo gestor do } \\
\text { projeto. Controle } \\
\text { centralizado. }\end{array}$ & $\begin{array}{l}\text { Gestores de projetos alocados } \\
\text { exclusivamente nos projetos. } \\
\text { Mudanças de prazos e custos }> \\
5 \% \text { do orçado necessitam de } \\
\text { aprovação da gerência superior }\end{array}$ \\
\hline $\begin{array}{l}\text { Recursos } \\
\text { Humanos }\end{array}$ & $\begin{array}{l}\text { Terceirizados na execução e } \\
\text { próprios no gerenciamento }\end{array}$ & $\begin{array}{l}\text { Próprios e terceirizados. } \\
\text { Excesso de ativida-des da } \\
\text { equipe envol-vidos - sem } \\
\text { tempo para novas alocações }\end{array}$ & $\begin{array}{l}\text { Terceirizados na execução e } \\
\text { próprios no gerenciamento }\end{array}$ \\
\hline $\begin{array}{l}\text { Risco predo- } \\
\text { minante }\end{array}$ & $\begin{array}{l}\text { Impactar o trabalho da } \\
\text { Presidência e Diretoria } \\
\text { instaladas no prédio }\end{array}$ & $\begin{array}{l}\text { Impactar a oferta de re- } \\
\text { feições para os fun- } \\
\text { cionários: filas de espera e } \\
\text { insatisfação. }\end{array}$ & $\begin{array}{l}\text { Atrasos de cronograma e } \\
\text { insatisfação do cliente }\end{array}$ \\
\hline Resultado & $\begin{array}{l}\text { Prazo não cumprido devido a } \\
\text { frequentes alterações de escopo. } \\
\text { Preocupação com a qualidade }\end{array}$ & $\begin{array}{l}\text { Atendeu prazo e custo. Não } \\
\text { atendeu expectativa de } \\
\text { qualidade do cliente }\end{array}$ & $\begin{array}{c}\text { Foram atendidos todos os } \\
\text { requisitos (prazo, custo, } \\
\text { qualidade) com pequenas } \\
\text { variações em relação ao previsto }\end{array}$ \\
\hline
\end{tabular}

Fonte: Autoria própria (2011) 


\subsection{Projeto da GSIE: reforma do edifício da cúpula executiva da empresa}

Custo: Era meta do projeto realizá-lo no menor custo final. Era de responsabilidade do gestor do projeto apresentar alternativas que gerassem menores custos, seja na contratação dos serviços, na aquisição dos materiais ou até na escolha da melhor estratégia para a reforma. O trabalho no decorrer do projeto era controlar este planejamento dentro do custo orçado. A empresa contratada para gerenciar as atividades transmitia toda a informação do controle financeiro por andar, o custo por cada fornecedor e por contrato. Quem fazia o pagamento desses fornecedores era a própria empresa gerenciadora contratada.

Estrutura/Comunicação: O gestor do projeto encontrava-se no topo e possuía autonomia para delegar tarefas ao seu fornecedor principal. A este cabia o papel de realizar o projeto interno, gerenciando seus subcontratados para execução dos serviços dentro do prazo, custo e qualidade proposta no planejamento. Este tipo de estrutura tinha a vantagem de centralização de cobrança para o cumprimento do planejamento, porém em caso de desvios do planejamento, o caminho percorrido para que estes fossem corrigidos era mais longo. Observou-se a existência de documentações para controle das etapas de execução das atividades do projeto como o cronograma, ata de reuniões e plano de ação atualizados semanalmente.

Qualidade: A importância do projeto era tão grande que existia uma reserva financeira para casos de emergência ou necessidade de readequação do escopo por solicitação do cliente. Paralelo ao planejamento inicial das atividades, foi feito um plano de ação para as correções dos serviços já executados, enfatizando a preocupação em realizar todos os serviços com qualidade garantindo a satisfação do cliente. A relação com o cliente era constante. Cada andar do edifício possuía um ponto focal, no qual eram transmitidas as informações do andamento do projeto. Para isso foi elaborado uma agenda para visitações ao local, verificando o andamento do projeto e também registrando as considerações que estes pontos focais tinham a informar para melhoria do projeto.

Risco: O projeto tinha como principal desafio não impactar no trabalho dos profissionais da presidência e diretoria da empresa que ali estavam instalados. Foi preciso acompanhar em tempo integral as atividades para que qualquer desvio no planejamento fosse instantaneamente corrigido. Foi elaborado um plano de gestão de mudanças que estabelecia quando cada funcionário teria que liberar seu escritório, onde teria que se instalar no momento em que seu andar fosse reformado e quanto tempo cada andar ficaria inativo. Qualquer desvio ocorrido geraria um impedimento das atividades dos executivos e conseqüentemente impactos na empresa como um todo.

Contratação: A única contratação foi da empresa gerenciadora do projeto. Todas as demais contratações de serviços e materiais eram feitas por intermédio desta empresa.

Alocação de recursos humanos: Depois do início efetivo do projeto, o gestor do projeto viu-se na liberdade de focar suas atividades em outros projetos que estava gerenciando 
paralelamente a este. $\mathrm{O}$ gestor do projeto era funcionário de outra gerência localizada em outro município, distante do local de execução do projeto. A previsão para sua permanência no local do projeto foi extrapolada em mais de $100 \%$ do previsto, gerando uma necessidade de retornar ao seu local de trabalho para cuidar de outros projetos. Foi observado que os gestores de projetos na empresa estão envolvidos em mais de um projeto. Ás vezes possuem projetos completamente distintos, em localidades distintas, dividindo tempo e atenção das atividades de gerenciamento.

Resultado: O prazo previsto para execução não foi cumprido. O projeto teve uma dimensão maior do que a esperada, porque de acordo com o andamento da reforma, descobriam-se outras atividades com necessidade de execução que não estavam planejadas.

\subsection{Projeto da GIPP: ampliação da cozinha do restaurante central}

Custo: A autonomia para elaborar o orçamento do projeto era da gerência executora, porém o custo do projeto sofreu alterações (aumento de 3\%) devido ao acréscimo no escopo, que teve três revisões. Esse acréscimo não impactou no prazo final do projeto, uma vez que o orçamento teve sua alteração por substituição dos equipamentos por solicitação do cliente e não por aumento de atividades.

Estrutura/Comunicação: Eram realizadas reuniões semanais programadas, registradas por meio de atas, com a presença de todos os profissionais envolvidos nos assuntos abordados, em sua maioria toda a equipe do projeto ou seus representantes. Foi detectada apenas uma reunião nãoprogramada, realizada pouco antes no início efetivo do projeto que objetivava envolver todos os profissionais executantes de atividades no projeto e também garantir uma comunicação formal para iniciação do projeto. Também foi considerada fundamental para informar sobre o acréscimo no escopo, que mesmo restringindo mudanças nas atividades de uma equipe específica (suprimentos), também poderia influenciar indiretamente nas demais atividades planejadas para execução do projeto.

Alocação de recursos humanos: Para gerenciar a distribuição de atividades dos atores envolvidos no projeto foi elaborada uma matriz de responsabilidade que permitiu ao gestor visualizar um excesso de atividades atribuídas aos profissionais. Porém a execução do projeto não podia esperar o remanejamento de mais profissionais ou novas contratações. O projeto surgiu devido a uma crescente demanda de refeições no complexo industrial. O restaurante já não comportava a preparação de uma quantidade suficiente de refeições diárias. Era uma corrida contra o tempo.

Qualidade: Um fator ausente no gerenciamento do projeto em análise foi uma equipe responsável pelo acompanhamento e controle da qualidade do produto. A execução do projeto atendeu tecnicamente aos requisitos solicitados pelo cliente, mas o acompanhamento da qualidade 
era realizado pelos próprios profissionais executantes. Conseqüência disto foi a ausência de comunicação direta sobre os desvios ocorridos durante a execução das atividades. Por mais que informações sobre o andamento das atividades chegassem ao gestor do projeto, o percurso existente não permitia que os reajustes necessários fossem imediatamente executados. Porém, vale ressaltar que toda e qualquer mudança ocorrida na execução das atividades previamente planejadas só era executada com autorização do gestor, garantindo uma comunicação para cumprimento de procedimentos. A execução do projeto contou com uma empresa terceirizada responsável pela alocação dos recursos necessários para as atividades operacionais do projeto. Isso, mais uma vez, facilitou a execução da parte técnica das atividades, mas não a garantia de a qualidade epserada do serviço executado.

Problemas identificados: Uma deficiência encontrada no gerenciamento de projetos dessa gerência e evidenciada neste projeto foi a não utilização de "lições aprendidas" em projetos anteriores. As deficiências detectadas em projetos anteriores não eram utilizadas como prevenção de desvios futuros, minimizando os erros já cometidos. Outro problema identificado por meio da análise da declaração do escopo do projeto foi que as premissas não estavam bem definidas. Certamente esse item contribuiu para a execução de projeto sem a previsão de acontecimentos negativos, que poderiam gerar o fracasso do projeto.

Resultados: O projeto foi executado dentro do prazo e custo planejado. Porém a expectativa do cliente não foi considerada totalmente atendida. Por se tratar de um projeto estrutural, a performance da planta foi um pouco abaixo do projetado. Até a data de elaboração deste estudo, reparos e correções estavam sendo realizados. Foi observada uma forte preocupação quanto ao cumprimento técnico das obrigações para garantia de conclusão dentro do planejado. Contudo, a preocupação com a qualidade do produto final não foi prioridade do projeto.

\subsection{Projeto da GDTI: novo sistema de informação}

Custo: O custo final do projeto sofreu alterações (redução de 5,2\%), porém isso não ocorreu por um gerenciamento eficaz, mas sim por fatores externos não controláveis, variação dos custos de bens e serviços de terceiros e variação de câmbio do dólar. Esses fatores externos geraram conseqüências positivas para o gerenciamento, mas que não estavam sob o domínio da equipe do projeto.

Prazo: O tempo efetivamente utilizado para execução do projeto se estendeu em $1 \%$ devido a variações dos prazos de entrega de bens e serviços de terceiros. O que se observou nesse projeto é que por mais que a empresa seja a responsável pela execução do projeto, as atividades operacionais estavam sempre "em mãos" de terceiros. Apesar desta autonomia de decisões, o andamento do 
projeto dependia de uma junção de gerenciamento da empresa com a execução de atividades pelos fornecedores.

Estrutura/Comunicação: O controle do andamento das atividades era feito por meio de reuniões curtas e frequentes (quinzenais), registradas em atas. Essas reuniões abordavam assuntos básicos referentes ao andamento do projeto. Participavam todos os profissionais envolvidos nos assuntos abordados, em sua maioria toda a equipe do projeto ou seus representantes. Assuntos pontuais que surgiam durante o andamento do projeto também exigiam reuniões, como forma de manter uma comunicação eficaz com todos os profissionais envolvidos. Os processos de gerenciamento ficavam centralizados nos gestores do projeto (do contratante e da contratada). A parte operacional (execução das atividades) foi dividida em várias equipes: equipe de software, equipe de hardware, equipe de especificação e controle de qualidade dos produtos, equipe de compras e contratações, equipe de treinamento. Houve centralização de gerenciamento do projeto. Os gestores possuíam o papel de planejamento do projeto, controle das atividades e gerenciamento da execução das etapas. A parte operacional era destinada aos fornecedores que possuíam a responsabilidade de execução de atividades programadas.

Riscos: O que contribuiu para o sucesso do projeto foi a elaboração de planos de ação para mudanças. Essas informações eram anexadas ao projeto e possuíam necessidade de cumprimento de prazos para que todo o planejamento (custo, tempo, qualidade e escopo) não fosse afetado. Cada equipe envolvida nas atividades listadas no plano era responsável pela execução dos itens ali descritos e do seu gerenciamento. Cobranças para cumprimento dos prazos eram realizadas pelo gestor do projeto. As informações sobre o andamento das atividades do projeto chegavam ao gestor pelos próprios profissionais envolvidos, o que acabava facilitando a decisão de correções nas atividades e cobrança para cumprimento dos prazos dentro do custo previsto. Entretanto, uma política interna da área estudada estabelece que toda mudanças de prazo e custo superior a 5\% do previsto requer aprovação do gerente superior.

Alocação de recursos humanos: Os gestores de projetos de TI da empresa são destinados exclusivamente aos projetos. Os profissionais das áreas de negócio da empresa (clientes de TI) que possuem papéis nos projetos de TI, entretanto, executam outras atividades quando não estão alocados a projetos. Esse modelo de utilização de recursos humanos gera conseqüências para o projeto. Quando o recurso é compartilhado com outras atividades, pode causar atrasos no cronograma, devido à concorrência pelo recurso.

Resultados: O projeto foi considerado um sucesso. Os indicadores gerenciais de desempenho (variações de custo, de prazo, de escopo e de qualidade) apresentaram resultados considerados excelentes. $\mathrm{O}$ projeto também atendeu a expectativa do cliente. 


\section{Considerações finais}

Para um gerenciamento de projetos com eficácia, as áreas analisadas buscam aprimoramento constante na utilização de suas metodologias em busca das melhores práticas de gestão. Atender as etapas desta gestão imposta na metodologia de PMI é algo já freqüente nas áreas em análise. Todas utilizam documentações e procedimentos que contribuem para realização de projetos com sucesso.

Para todas as gerências estudadas, observou-se a importância da utilização de uma metodologia de gerenciamento de projetos para sua gestão. Apesar de projetos maiores e mais complexos possuírem uma utilização mais efetiva da metodologia, a aplicação do gerenciamento de todas as áreas de conhecimento varia de acordo com a dimensão e a complexidade do projeto.

Um fator que contribuiu para o sucesso dos projetos, mesmo que parcial, foi a forma de planejamento, monitoramento e controle adotada por todas as gerências estudadas. Controlar o andamento das atividades dos projetos com reuniões e planos de ações para acompanhamento e correções de desvios garantiu aos gestores o alcance das metas dos projetos por eles gerenciados. Outro método de monitoramento e controle, o plano de mudanças, elaborado especificamente para o projeto Reforma do Edifício da Cúpula Executiva da Empresa, garantiu a satisfação do cliente e o cumprimento das metas do projeto. Adicionalmente, o controle dos custos e do cronograma por meio de relatórios gerenciais forneceu aos gestores informações atualizadas quanto ao andamento dos projetos, assegurando a confiança dos clientes dos projetos Reforma do Edifício e Novo Sistema de Intormação, principalmente.

Outra forma de controle que assegurou os projetos de desvios na execução de suas etapas foi a existência de um procedimento que garantisse o controle de mudanças na execução das atividades. A necessidade de autorização do gestor diante de qualquer mudança considerável possibilitou que este tivesse o conhecimento sobre toda alteração ocorrida.

Já a matriz de responsabilidade formulada no projeto Reforma do Restaurante Central, apesar de identificar o excesso de atividades atribuídas a um mesmo profissional, não pode ser reformulada, pela urgência de execução do projeto. Isso contribuiu consideravelmente para a existência de desvios na qualidade pré-estabelecida no planejamento do projeto.

O fato mais observado durante a análise dos dados foi a atuação destas áreas como prestadoras de serviços. Por mais que sejam executantes de atividades não rotineiras, que exigem aprimoramento cada vez maior e minimização de erros em suas atividades, foi percebido, na fala dos entrevistados, um amadurecimento crescente na gestão de projetos.

O ponto crucial observado nas entrevistas foi a importância que as gerências dão ao cliente. São estes os principais disseminadores da imagem de suas atividades por serem os mais impactados com a entrega de seus produtos, serviços ou resultados. 
Durante a análise percebeu-se a autonomia que os clientes possuíam para reestruturação das áreas dos projetos. Como são também os patrocinadores, estes se sentiam no direito de cobrar a execução dentro do prazo, custo, escopo e qualidade definido no planejamento. O que não pode ser considerado como incorreto, pois são eles os usuários dos produtos gerados com os projetos, exigindo, portanto, nada mais além do que o proposto inicialmente.

Não se pode considerar que um aumento no ciclo de vida ou aumento no custo previsto no projeto seja um determinante de fracasso se for por intermédio de uma solicitação do cliente. Porém o preocupante e observado no estudo em análise foi o excessivo atendimento às solicitações do cliente. Essa autonomia possui desvantagens perigosas para a imagem das áreas desenvolvedoras de projetos. Projetos que são muito reformulados e de excessivas revisões podem acarretar pontos negativos às áreas por se tornarem inacabos ou com ciclos de vida aparentemente distorcidos.

Contudo, o que torna uma área executora de gerenciamento de projetos eficaz é exatamente a sabedoria em realizar a gestão de seu planejamento em conjunto com a necessidade e expectativa do cliente para que seus produtos sejam realizados com a qualidade solicitada e esperada pelo cliente durante toda sua execução.

O grande desafio, portanto, se resume na sua fase de iniciação. É preciso conquistar a confiança e aparentar total disponibilidade na prestação de seu serviço durante a etapa de planejamento, para que todas as expectativas do cliente sejam transformadas em requisitos que garantam a elaboração do escopo bem estruturado.

\begin{abstract}
The use of project management methodologies may enable professionals involved with projects to run their activities more efficiently and effectively. This study aimed to identify the actions used for project planning, monitoring and controlling, the level of involvement of managers with the project management tools and the result of using this way of management for project success. The research method was case study in three areas of a major mining company: Infrastructure Service Management, Production Project Implementation Management and Information Technology Development Management. Those areas were chosen because they provide internal services to the company and they are responsible for various projects. We interviewed three project managers in the three analyzed areas. The results showed the importance of applying project management methodology, regardless of the size of the project, although larger and more complex projects do demand a more effective use of the methodology. A common characteristic observed in the analyzed projects was the autonomy that clients had for restructuring the project plan. However the excessive consent to client's requests may cause excessive project revisions and apparently make distortions to project lifecycles. Nevertheless, what makes project management effective is exactly the care in making planning management together with client's needs and expectations so that the products are made with the quality required and expected by the client.
\end{abstract}

Key-words: Projects; Project Management; Methodology; Planning; PMI.

\title{
Referências
}

ATTARZADEH, I.; OW, S. H. Project management practices: success versus failure. In: International Symposium on Information Technology. Proceedings 2008.

BALACHANDRA, R.; FRIAR, J. H. Factors for success in R\&D projects and new product innovation: a contextual framework. IEEE Transactions on Engineering Management, v. 44, n. 3, p.276-287, 1997. 
BEDINGFIELD, J. D.; THAL JUNIOR., A. E. Project manager personality as a factor for success. PICMET 2008. Proceedings, 27-31 July, Cape Town, South Africa.

CHAN, A. P. C.; SCOTT, D.; CHAN, A. P. L. Factors affecting the success of a construction project. Journal of Construction Engineering and Management, v. 130, n.1, p.153-155, 2004.

cross ref

CHUA, D. K. H.; KOG, Y. C.; LOH, P. K. Critical success factors for different project objectives. Journal of Construction Engineering and Management, v. 125, n.3, p.142-150, 1999.

cross ref

COOKE-DAVIES, T. The "real”' success factors on projects. International Journal of Project Management, v. 20, p.185-190, 2002.

cross ref

DENNI-FIBERESIMA, D.; RANI, N. S. A. An evaluation of critical success factors in oil and gas project portfolio in Nigeria. African Journal of Business Management, v.5 n.6, p.2378-2395, 2011.

DINSMORE, P. C.; SILVEIRA NETO, F. H. Gerenciamento de projetos: como gerenciar seu projeto com qualidade, dentro do prazo e custos previstos. Rio de Janeiro: Qualitymark, 2005.

DVIR, D.; LIPOVETSKY, S.; SHENHAR, A.; TISHLER, A. In search of project classification: a non-universal approach to project success factors. Research Policy, vol. 27, p.915-935, 1998.

cross ref

HENDERSON, Linda S. Encoding and decoding communication competencies in project management: an exploratory study. International Journal of Project Management, vol. 22, p.469-476, 2004.

cross ref

HOPE, K. L.; AMDAHL, E. Configuring designers? Using one agile project management methodology to achieve user participation. New Technology, Work and Employment, v. 26, n. 1, p.54-67, 2011.

cross ref

JONAS, D. Empowering project portfolio managers: how management involvement impacts project portfolio management performance. International Journal of Project Management, v. 28, p. 818-831, 2010.

cross ref

JUGDEV, K.; MÜLLER, R. A retrospective look at our evolving understanding of project success. Project Management Journal, v. 36, n. 4, p.19-31, 2005.

KELLING, R. Gestão de projetos: uma abordagem global. São Paulo: Saraiva, 2002.

KUEN, C. W.; ZAILANI, S.; YUDI, F. Critical factors influencing the project success amongst manufacturing companies in Malaysia. African Journal of Business Management, v.3, n. 1, p. 16-27, Jan. 2009.

LAVAGNON, A. I; DIALLO, A; THUILLIER, D. Critical success factors for World Bank projects: an empirical investigation. International Journal of Project Management, v. 30, p. 105-116, 2012.

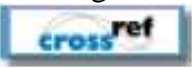

LIM, C. S.; ZAIN, M. M. Criteria of project success: an exploratory re-examination. International Journal of Project Management, v. 17, n. 4, p.243-248, 1999.

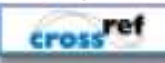

LOVE, P. E. D.; MISTRY, D.; DAVIS, P. R. Price competitive alliance projects: identification of success factors for public clients. Journal of Construction Engineering and Management, v.136, n. 9, p. 947-956, 2010.

cross ref 
MALACH-PINES, A.; DVIR, D.; SADEH, A. Project manager-project (PM-P) fit and project success. International Journal of Operations \& Production Management, v. 29 n. 3, p.268-291, 2009.

cross ref

MCHUGH, O; HOGAN, M. Investigating the rationale for adopting an internationally-recognised project management methodology in Ireland: the view of the project manager. International Journal of Project Management, v. 29 , p.637-646, 2011.

cross ref

MÜLLER, R.; TURNER, J. R. Attitudes and leadership competences for project success. Baltic Journal of Management, v. 5 n. 3, p.307-329, 2010.

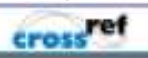

MUNNS, A. K.; BJEIRMI, B. F. The role of project management in achieving project success. International Journal of Project Management, v. 14, n. 2, p. 81-87, 1996.

cross ref

NELLORE, R.; BALACHANDRA, R. Factors influencing success in integrated product development (IPD) projects. IEEE Transactions on Engineering Management, v. 48, n. 2, p.164-174, 2001.

cross ref

NETTO, C. B. Gerenciamento de projetos com visão do PMI. Vitória: Time-Now Treinamentos, 2007.

PATÉ-CORNELL, M. E.; DILLON, R. L. Success factors and future challenges in the management of faster-bettercheaper projects: lessons learned from NASA. IEEE Transactions on Engineering Management, v. 48, n. 1, p. 2535, 2001.

cross ref

PINTO, J. K.; SLEVIN, D. P. Critical success factors in effective project implementation. In: Project Management Handbook. 2nd Edition. Chapter 20. John Wiley \& Sons, 2008.

PMI Brasil. Estudo de benchmarking em gerenciamento de projetos. Brasil 2007. Disponível em:

<www.pmi.org.br>. Acesso em: 6 set. 2008.

PMI. Project Management Institute. Um guia do conjunto de conhecimentos em gerenciamento de projetos (guia PMBOK®). 3. ed. Newtown Square: Four Campus Boulevard, 2004.

RODRIGUEZ-REPISOA, L.; SETCHIB, R.; SALMERONC, J. L. Modelling IT projects success: emerging methodologies reviewed. Technovation, v. 27, p. 582-594, 2007.

cross ref

SAVOLAINEN, P.; AHONEN, J. J.; RICHARDSON, I. Software development project success and failure from the supplier's perspective: a systematic literature review. International Journal of Project Management, v. 30, p. 458469, 2012.

cross ref

SUHONEN, M.; PAASIVAARA, L. Factors of human capital related to project success in health care work units. Journal of Nursing Management, v.19, p. 246-253, 2011.

cross ref

TISHLER, A.; DVIR, D.; SHENHAR, A.; LIPOVETSKY S. Identifying critical success factors in defense development projects: a multivariate analysis. Technological Forecasting and Social Change, v. 51, p. 151-171, 1996.

cross ref

TURNER, J. R.; MÜLLER, R. The project manager's leadership style as a success factor on projects: a literature review. Project Management Institute, v. 36, n. 1, p. 49-61, 2005. 
VALERIANO, D. L. Moderno gerenciamento de projeto. São Paulo: Prentice Hall, 2005.

VEIRA, M. F. Gerenciamento de projetos de tecnologia da informação. Rio de Janeiro: Elsevier, 2003.

WATERIDGE, J. IT projects: a basis for success. International Journal of Project Management, v. 13, n. 3, p. 169$172,1995$.

cross ref

WIT, A. Measurement of project success. Project Management, v 6, n. 3, p. 165-170, 1988.

\section{Dados dos autores:}

\section{Nome: Mariana Moura Abreu}

Filiação institucional: Universidade Federal do Espírito Santo

Departamento: Administração

Função ou cargo ocupado: Estudante

Endereço completo para correspondência: Rua Heitor de Andrade, 200, Apto 11A - Jardim das Industriais - São José dos Campos/SP - Brasil - CEP: 12.241-000.

Telefones para contato: (12) 8809-4130

e-mail: mariana.m.abreu@hotmail.com; mabreu5@its.jnj.com

\section{Nome: Teresa Cristina Janes Carneiro}

Filiação institucional: Universidade Federal do Espírito Santo

Departamento: Administração

Função ou cargo ocupado: Professor

Endereço completo para correspondência: Av. Dante Micheline, 2207/502 - Mata da Praia Vitória/ES - Brasil - CEP: 29066-430.

Telefones para contato: (27) 3324-0776 / (27) 9925-9795

e-mail: carneiro.teresa@gmail.com

Recebido em: 11/11/2011

Aceito em: 16/10/2012 